\title{
Kwestionariusz Speech, Spatial and Qualities of Hearing Scale (SSQ) - przegląd literatury
}

\section{Speech, Spatial and Qualities of Hearing Scale (SSQ) - the literature review}

\section{Karolina Dajos-Krawczyńska}

Instytut Fizjologii i Patologii Słuchu, Światowe Centrum Słuchu, Warszawa/Kajetany

Adres autora: Karolina Dajos-Krawczyńska, Światowe Centrum Słuchu, ul. Mokra 17, Kajetany, 05-830 Nadarzyn, e-mail: kdajos@gmail.com

\begin{abstract}
Streszczenie
Lokalizacja źródła dźwięku oraz rozumienie mowy to zdolności i umiejętności słuchowe, które stanowią podstawę funkcjonowania człowieka. Badania kliniczne, chociaż pozwalają na obiektywną ocenę tych umiejętności, często nie odzwierciedlają rzeczywistego funkcjonowania osoby niesłyszącej, ponieważ warunki akustyczne podczas badania znacznie różnią się od warunków akustycznych spotykanych w codziennym życiu. Jednym z narzędzi, które pozwalają na ocenę subiektywnych trudności w zakresie lokalizacji dźwięku i rozumienia mowy w różnych sytuacjach akustycznych, jest kwestionariusz Speech, Spatial and Qualities of Hearing. Celem pracy było omówienie kwestionariusza oraz jego przydatności w badaniach klinicznych i eksperymentalnych.
\end{abstract}

Słowa kluczowe: kwestionariusz • lokalizacja dźwięku • rozumienie mowy

\begin{abstract}
Such abilities as sound localization and speech understanding are the basis of human functioning. In clinical trials it is possible to objectively assess these skills, but results of these tests often do not reflect real difficulties experienced by patients, because acoustic conditions during tests differ significantly from the acoustic environment encountered in everyday life. The questionnaire Speech, Spatial and Qualities of Hearing is one of the tools, that allow to assess subjective difficulties in terms of sound localization and speech understanding in various listening situations. The aim of this study was to discuss the questionnaire and its usefulness in clinical and experimental studies.
\end{abstract}

Key words: questionnaire • sound localization • speech understanding

\section{Wprowadzenie}

Środowisko akustyczne, w którym żyjemy, jest niemałym wyzwaniem dla układu słuchowego - docierają do niego dźwięki, często $\mathrm{z}$ wielu kierunków, o różnym natężeniu, wysokości i barwie. Nierzadko dźwięki te nakładają się na siebie, są dynamiczne, często również nagle i szybko się zmieniają. Aby efektywnie funkcjonować w tym środowisku, niezbędne jest sprawne działanie układu słuchowego, pozwalające na identyfikację dźwięków pożądanych, przy jednoczesnym kontrolowaniu dźwięków stanowiących tło akustyczne. Kiedy pojawia się nowy dźwięk, układ słuchowy musi zlokalizować jego źródło, ocenić jego istotność, a jeśli to konieczne również w odpowiedni sposób na niego zareagować [1,2].

Gatehouse i Noble [1] wskazują, że w typowych badaniach klinicznych ocenie poddawane jest rozumienie takich sygnałów akustycznych, które mają stałą i przewidywalną charakterystykę widmową/czasową, często w obecności pojedynczego źródła hałasu, który również jest statyczny i przewidywalny. Takie warunki badania nie oddają rzeczywistych sytuacji akustycznych.

Kwestionariusz Speech, Spatial and Qualities of Hearing został opracowany przez Gatehouse'a i Noble'a [1] w celu oceny stopnia trudności słuchowych doświadczanych w różnych sytuacjach w codziennym życiu. Kwestionariusz stanowi uzupełnienie badań audiometrycznych czułości słuchu - jest wskaźnikiem tego, jak ewentualny ubytek słuchu wpływa na codzienne funkcjonowanie.

Skala SSQ pozwala na subiektywną ocenę trudności doświadczanych w trzech aspektach:

- rozumienie mowy - w różnych sytuacjach akustycznych (w ciszy, w hałasie, w grupie osób, w pomieszczeniach z pogłosem); 
1. Yoy are talking with one other person and there is a TV on in the same room. Without turning the TV down, can you follow what the person you're talking to says?

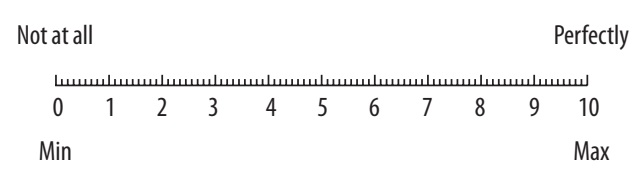

Tick if not appliacble

or wouldn't hear it

Rycina 1. Skala odpowiedzi kwestionariusza SSQ (źródło: [1])

Figure 1. The scale of answers in SSQ (source: [1])

- słyszenie przestrzenne - lokalizacja źródła dźwięku, w tym kierunku, odległości, ruchu;

- jakość słyszenia - rozpoznawanie i segregowanie dźwięków, łatwość słuchania, poziom naturalności dźwięku $[1,2]$.

Kwestionariusz SSQ używany jest przede wszystkim do oceny korzyści z różnego rodzaju urządzeń wspomagających słyszenie - aparatów słuchowych, aparatów na przewodnictwo kostne, a także implantów ślimakowych. Skalę SSQ często stosuje się również u osób z jednostronnym ubytkiem słuchu (np. po operacjach usunięcia nerwiaków nerwu słuchowego), a także u osób z prawidłowym słuchem [2,3].

Kwestionariusz został opracowany w języku angielskim, następnie przetłumaczony i wystandaryzowany w kilku innych językach - m.in. niemieckim, duńskim, francuskim, hiszpańskim, włoskim, japońskim, a także w języku polskim. Wszystkie wersje kwestionariusza (również wersja w języku polskim) dostępne są bezpłatnie na stronie MRC Institute of Hearing Research (www.ihr.mrc.ac.uk/ pages/products/ssq).

\section{The Speech, Spatial and Quality of Hearing - kwestionariusz dla dorosłych}

Pierwszą wersją kwestionariusza była skala dla osób dorosłych, opracowana przez Gatehouse’a i Noble’a w 2004 roku. Kwestionariusz składa się z 3 części (łącznie 49 pytań), dotyczących kolejno rozumienia mowy, słyszenia przestrzennego oraz jakości słyszenia.

Część pierwsza składa się z 14 pytań, które dotyczą zdolności rozumienia mowy w szerokim zakresie warunków akustycznych - od obecności sygnałów konkurujących, przez liczbę i widoczność osób uczestniczących w rozmowie, po różnice tła akustycznego (cisza, pogłos, szum i hałas) [1]. Część pytań dotyczy również umiejętności słyszenia obuusznego i rozdzielnousznego (dwóch i więcej źródeł dźwięku w tym samym czasie), selektywnej uwagi słuchowej, zdolności percepcji bodźców, które szybko zmieniają się w czasie [1].

W części drugiej znajduje się 17 pytań dotyczących umiejętności związanych ze słyszeniem przestrzennym - między innymi oceny kierunku i odległości, a także poruszania się źródła dźwięku. W tej części znajdują się również pytania dotyczące umiejscowienia dźwięku („w głowie” lub w „otoczeniu”), co ma szczególne znaczenie w przypadku pacjentów korzystających $\mathrm{z}$ aparatu słuchowego [1].

Trzecia część kwestionariusza (18 pytań) dotyczy innych funkcji słuchowych (między innymi segregacji i rozpoznawania dźwięków) oraz jakości słyszenia (naturalność, wysiłek słuchowy). Pytania odnoszą się do zdolności rozpoznawania i segregacji dźwięków mowy, np. rozpoznawania jednocześnie dwóch bodźców jako różnych, oddzielnych dźwięków. W zakresie jakości słyszenia pytania dotyczą nie tylko jakości słyszanych dźwięków, lecz także umiejętności odczytywania emocji z wypowiedzi innych osób oraz odczucia naturalności własnego głosu. W tej części kwestionariusza zawarte są również pytania odnoszące się do wysiłku wkładanego w rozumienie konwersacji, szczególnie w grupie osób lub w hałasie [1].

Sposób odpowiedzi na pytania w każdej części kwestionariusza jest taki sam. Osoba badana zaznacza swoją odpowiedź na skali od 0 do 10 , przy czym „0" oznacza największe trudności (lub w ogóle brak umiejętności), natomiast 10 brak trudności związanych $\mathrm{z}$ daną umiejętnością słuchową (rycina 1) [1]. Wynikiem kwestionariusza jest średnia uzyskana z sumy wszystkich odpowiedzi. Możliwe jest uzyskanie wyniku dla całego kwestionariusza (średnia obliczona na podstawie wszystkich odpowiedzi), jak również dla każdej sekcji osobno (średnia obliczona na podstawie odpowiedzi na pytania w danej sekcji). Kwestionariusz może być przeznaczony do samodzielnego wypełniania, jednak Gatehouse i Noble w swoich pracach preferowali technikę wywiadu, prowadzonego przez wykwalifikowanych audiologów, co pozwalało upewnić się, że każde pytanie zostało właściwie zrozumiane przez każdego z uczestników badania [1].

\section{Kwestionariusz SSQ dla dzieci}

Galvin i wsp. [2,4] dokonali adaptacji kwestionariusza SSQ dla populacji dziecięcej. Celem autorów było opracowanie takiej wersji kwestionariusza, która będzie odpowiednia i zrozumiała dla dzieci. Wymagało to zmiany tych pytań, które w grupie dzieci nie miały zastosowania (np. rozumienie mowy podczas prowadzenia auta) lub modyfikacji pytań, tak aby były dostosowane do trybu życia i funkcjonowania dziecka (np. rozumienie mowy podczas rozmowy w restauracji). Struktura kwestionariusza, w tym podział na trzy części, a także forma i skala odpowiedzi pozostały bez zmian (rycina 2) [2,4]. W kwestionariuszu dla dzieci pojawiła się jednak dodatkowa odpowiedź - „nie wiem” [SSQ dla dzieci].

Kwestionariusz SSQ został przygotowany w trzech wersjach: dla dzieci, dla rodziców/opiekunów oraz dla nauczycieli. W skalach przeznaczonych dla rodziców i nauczycieli zawarto dodatkowo tzw. okres obserwacji przed wypełnieniem kwestionariusza, podczas którego dzieci miały być obserwowane w sytuacjach, których dotyczą pytania. Zadaniem rodziców była również ocena, jak często dziecko uczestniczy w sytuacjach opisanych w kwestionariuszu $[5,6]$. 
1. Yoy are talking with one other person and there is a TV on in the same room. Without turning the TV down, can you follow what the person you're talking to says?

\section{Comparing your ability now with your ability before getting your hearning aid/s}

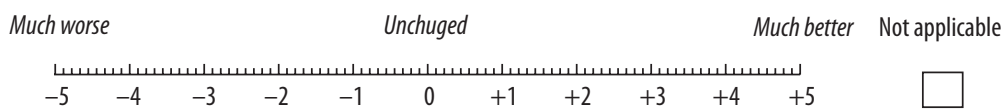

Rycina 2. Przykładowe pytanie oraz skala odpowiedzi kwestionariusza SSQ dla dzieci (źródło: arkusz kwestionariusza SSQ dla dzieci)

Figure 2. Sample question and the scale of answers in SSQ for children (source: SSQ for children)

1. Yoy are talking with you Mum and Dad and there is a TV on in the same room. Without turning the TV down, can you understand what your Mum and Dad is saying to you?
Not at all
Minimum
$\quad$ Would not hear it
Not applicable Maximum

Rycina 3. Skala odpowiedzi kwestionariusza SSQ-B (źródło: [8])

Figure 3. The scale of answers in SSQ-B (source: [8])

Kwestionariusz przeznaczony jest dla dzieci od około 11 . roku życia. Wiek ten zdeterminowany jest przede wszystkim długością kwestionariusza oraz rodzajem odpowiedzi, które wymagają odpowiedniego poziomu rozwoju poznawczego i językowego. W przypadku kwestionariuszy dla rodziców i nauczycieli możliwe jest dokonanie oceny u dzieci nieco młodszych, jednak należy wziąć pod uwagę możliwy wpływ innych czynników (np. młodsze dzieci łatwiej się rozpraszają), które mogą zmniejszać wiarygodność wyników [2,4].

\section{Skrócona wersja SSQ - SSQ12}

Noble i wsp. [7] opracowali skróconą wersję kwestionariusza SSQ, składającą się z 12 pytań wyodrębnionych z pełnej wersji kwestionariusza. Według autorów, krótsza wersja może być użyteczna w badaniach kontrolnych u osób w trakcie terapii, np. w celu oceny doświadczanych trudności przed rehabilitacją i po jej zakończeniu.

Badania przeprowadzone w grupie 1220 osób wykazały, że skrócona wersja kwestionariusza zapewnia wyniki zbliżone do tych uzyskanych w pełnej wersji kwestionariusza SSQ (w przypadku krótszej wersji obserwowane są nieco niższe średnie wyniki niż w kwestionariuszu SSQ) [7].

Inną skróconą wersję kwestionariusza opracowali Demeester i wsp. (2012). Składała się ona z 5 pytań (SSQ5). Według autorów, kwestionariusz ten stanowił wiarygodne narzędzie do badań przesiewowych, a analiza wyników wykazała, że ma on odpowiednią czułość i specyficzność [za: 7]. Z kolei Kiessling i wsp. (2011) w swoich badaniach wykorzystali wersję SSQ składającą się z 15 pytań [za: 7].

\section{Badania z użyciem kwestionariusza SSQ}

Gatehouse i Noble [1] prowadzili badania z użyciem pierwszej wersji kwestionariusza w grupie 153 osób dorosłych, u których ubytek słuchu wynosił średnio $38,8 \mathrm{~dB}$ w uchu lepiej słyszącym i 52,7 dB w uchu gorzej słyszącym. Średni ogólny wynik kwestionariusza wyniósł 5,5 punktu (SD 1,9). Analiza wykazała, że pomiędzy wynikiem kwestionariusza SSQ a średnim progiem słyszenia $\mathrm{w}$ audiometrii tonalnej zachodzą umiarkowane korelacje - współczynnik korelacji wyniku SSQ ze średnim progiem słyszenia ucha z mniejszym ubytkiem słuchu wynosił $-0,51$, natomiast ze średnim progiem słyszenia ucha z większym ubytkiem słuchu 0,52 [1]. Autorzy dokonali dwukrotnie oceny korelacji pomiędzy poszczególnymi pytaniami kwestionariusza - najpierw ocenili bezpośrednie korelacje pomiędzy pytaniami, a następnie korelacje $\mathrm{z}$ uwzględnieniem ucha lepiej i gorzej słyszącego. Wykazano, że niemal wszystkie pytania w kwestionariuszu mają współczynniki korelacji powyżej 0,5 [1].

Jensen i wsp. [8] prowadzili badania z użyciem kwestionariusza SSQ w grupie osób przed dopasowaniem i po dopasowaniu aparatu słuchowego. Stosowali oni specjalnie opracowaną wersję kwestionariusza, tzw. SSQ-B (ang. benefit), którego głównym celem jest ocena korzyści uzyskanych z aparatu słuchowego [8]. Kwestionariusz SSQ-B składa się z tych samych pytań, jednak ma nieco inną skalę odpowiedzi - od -5 do 5 , przy czym -5 oznacza słyszenie dużo gorzej w aparacie słuchowym niż bez aparatu, natomiast 5 - znacznie lepsze słyszenie w aparacie słuchowym (rycina 3) [8]. Analiza kwestionariuszy wykazała, że sytuacje sprawiające najwięcej trudności wg kwestionariusza SSQ oraz korzyści z aparatów słuchowych w tych sytuacjach (ocenione w SSQ-B) są ocenione zgodnie z oczekiwaniami autorów. Na podstawie uzyskanych wyników autorzy potwierdzili również zasadność opracowania kwestionariusza SSQ-C (ang. comparative), służącego do porównania korzyści odnoszonych podczas stosowania dwóch różnych aparatów słuchowych [8].

Doss i wsp. [5] przeprowadzili badania z użyciem kwestionariusza SSQ oraz SSQ-B i SSQ-C u osób dorosłych korzystających z aparatów słuchowych w celu oceny korzyści $\mathrm{z}$ nowego typu aparatu. Wyniki kwestionariusza wskazały, że stosowanie nowego rodzaju aparatu daje lepsze korzyści 
słuchowe $\mathrm{w}$ porównaniu $\mathrm{z}$ innym aparatem słuchowym. Osoby, dla których nowy typ aparatu był pierwszym stosowanym aparatem, zgłaszały istotną poprawę w zakresie wszystkich obszarów kwestionariusza [5].

Akeroyd i wsp. [3] dokonali analizy czynnikowej wyników kwestionariusza SSQ z grupy 1220 osób dorosłych, podzielonych na 3 grupy - osoby bez aparatów słuchowych, $\mathrm{z}$ jednym aparatem słuchowym i osoby aparatowane obustronnie. Autorzy wyróżnili 3 obszary (rozumienie mowy, percepcja przestrzenna oraz jasność, separacja i identyfikacja), a następnie oceniali stopień, w jakim poszczególne pytania kwestionariusza odzwierciedlają wyróżnione obszary. Na tej podstawie wyróżnili łącznie 35 pytań, w których korelacja okazała się największa (w kwestionariuszu SQQ łącznie jest 49 pytań) [3].

Ponieważ kwestionariusz SSQ przeznaczony jest głównie dla osób z różnego rodzaju ubytkami słuchu, niewiele jest badań na temat wyników kwestionariusza u osób z prawidłowym słuchem. Zahorik i wsp. [10] zbadali 233 młode osoby dorosłe o prawidłowej czułości słuchu. Pomimo tego, że obserwowano znaczną zmienność odpowiedzi, a także wielu młodych słuchaczy nie oceniło swoich zdolności słuchowych na najwyższym poziomie, uzyskane wartości wg autorów można uznać za normatywne [10].

Kwestionariusz SSQ znajduje zastosowanie również w badaniach u osób z implantami ślimakowymi. Noble i wsp. [11] przeprowadzili badania w grupie osób implantowanych jednousznie, obuusznie oraz u osób z implantem ślimakowym w jednym uchu i aparatem słuchowym $\mathrm{w}$ drugim uchu. Wyniki zastosowanych kwestionariuszy wskazują, że osoby we wszystkich grupach uzyskują znaczną korzyść słuchową po implantacji. W grupie osób młodszych implantowanych obuusznie zaobserwowano znacznie lepsze subiektywne oceny zdolności słuchowych, co potwierdza skuteczność procedury implantowania obuusznego [11]. Natomiast w grupie osób starszych z dwoma implantami obserwowano znacznie większą zmienność odpowiedzi, co może wskazywać na duży wpływ wieku oraz indywidualnych zdolności integracji informacji słuchowych docierających do obojga uszu [11].

Singh i wsp. [12] oszacowali powtarzalność wyników kwestionariusza SSQ u osób w wieku podeszłym. Badania zostały przeprowadzone dwukrotnie, w odstępie 6 miesięcy. Kiedy kwestionariusz przeprowadzany był przez wykwalifikowanego specjalistę, współczynnik korelacji pomiędzy wynikami kwestionariuszy wynosił 0,83 , jednak kiedy kwestionariusz był wypełniany samodzielnie przez osobę badaną, współczynnik korelacji był znacznie niższy i wynosił 0,65. Z kolei współczynnik powtarzalności wyznaczony przez Cronbacha (2010) [za: 3] w badaniach u osób dorosłych wynosił 0,96 (kwestionariusze były wypełniane samodzielnie, ale w razie wątpliwości wykwalifikowana osoba tłumaczyła wszelkie niejasności).

\section{Podsumowanie}

Za pomocą kwestionariusza SSQ można zbadać kilka zjawisk związanych z niedosłuchem, które nie mogą być poddane ocenie podczas standardowego badania czułości słuchu - jest odzwierciedleniem subiektywnych trudności odczuwanych przez danego pacjenta związanych z ubytkiem słuchu. $Z$ tego powodu może być cenną pomocą dla protetyków słuchu, a także osób prowadzących rehabilitację osób niesłyszących.

Publikacja powstała $w$ zwiazku $z$ realizacja projektu pn. „Zintegrowany system narzędzi do diagnostyki i telerehabilitacji schorzeń narządów zmystów (stuchu, wzroku, mowy, równowagi, smaku, powonienia)" INNOSENSE, wspólfinansowanego przez Narodowe Centrum Badań i Rozwoju w ramach Programu STRATEGMED.

\section{Piśmiennictwo:}

1. Gatehouse S, Noble W. The Speech, Spatial and Qualities of Hearing Scale (SSQ). Int J Audiol, 2004; 43: 85-89.

2. Galvin KL, Noble W. Adaptation of the Speech, Spatial, and Qualities of Hearing scale for use with children, parents, and teachers. Cochlear Implants Int, 2013; 14(3): 135-41.

3. Akeroyd MA, Guy FH, Harrison DL, Suller SL. A factor analysis of the SSQ (Speech, Spatial and Qualities of Hearing Scale). Int J Audiol, 2014; 53: 101-14.

4. Galvin K. The Speech, Spatial and Qualities of Hearing Scale (SSQ) for Teachers of the Deaf. 2013.

5. Galvin K. The Speech, Spatial and Qualities of Hearing Scale (SSQ) for Children with Impaired Hearing. 2013.

6. Galvin K. The Speech, Spatial and Qualities of Hearing Scale (SSQ) for Parents of Children with Impaired Hearing. 2013.

7. Noble W, Jensen NS, Naylor G, Bhullar N, Akeroyd MA. A short form of the Speech, Spatial and Qualities of Hearing scale suitable for clinical use: The SSQ12. Int J Audiol, 2013; 52(6): 409-12.
8. Jensen NS, Akeroyd MA, Noble W, Naylor G. The Speech, Spatial and Qualities of Hearing scale (SSQ) as a benefit measure. NCRAR conference on The Ear-Brain System: Approaches to the Study and Treatment of Hearing Loss. Portland, 2009 (plakat).

9. Doss Z, Henderson Sabes J. Assessment of the SSQ in a population of extended-wear hearing aid Wearers, 2010 (plakat).

10. Zahorik P, Rothpletz AM. Speech, Spatial, and Qualities of Hearing Scale (SSQ): Normative data from young, normal-hearing listeners. Meeting: Acoustical Society of America, 2014 (plakat).

11. Noble W, Tyler RS, Dunn CC, Bhullar N, Younger- and older-age adults with unilateral and bilateral cochlear implants: Speech and Spatial hearing self-ratings and performance. Otol Neurotol, 2009; 30(7): 921-29.

12. Singh G, Pichora-Fuller KM. Older adults' performance on the speech, spatial, and qualities of hearing scale (SSQ): test-retest reliability and a comparison of interview and self-administration methods. Int J Audiol, 2010; 49(10): 733-40. 